\title{
The Architectural Expression of Space and Form Created by the Light in the Works of Alvaro Siza
}

\author{
Chang Sung Kim¹, Kyung Wook Seo ${ }^{2 *}$ \\ ${ }^{1}$ Department of Architectural Engineering, Hyupsung University, Hwaseong Si, South Korea \\ ${ }^{2}$ Department of Architecture, Kyonggi University, Suwon, South Korea \\ Email: wook87@hotmail.com
}

Received 30 April 2014; revised 2 June 2014; accepted 14 June 2014

Copyright (C) 2014 by authors and Scientific Research Publishing Inc.

This work is licensed under the Creative Commons Attribution International License (CC BY). http://creativecommons.org/licenses/by/4.0/

c) (i) Open Access

\section{Abstract}

The light is an important element which helps people perceive objects. Therefore, it is important for architects to make the light and space be in harmony with each other. In this study, we analyzed the works of Alvaro Siza with a view to understand the conceptual value of the light expressed in his works and his principles in controlling it. According to the results of the study, the Siza's architecture is not a mere theoretical one trapped inside formality, but is a sensual and experiential one based on the locality. He was willing to use void spaces to invite the light in freeflowing plans, in order to invigorate and extend architectural spatiality to create deeper visual effect. In addition, the refined light in his works helped visitors experience the continuous forms and spaces by their own movements, while using the changes of the light to stimulate the interest of visitors and highlight the sequence of spaces.

\section{Keywords}

Alvaro Siza, Light, Form, Space

\section{Introduction}

The light helps to create an architectural space weaved with memories and adds sentimental feelings to it. The light also casts out darkness in relation with form to express the essence of the space. As such, the light is a fundamental element which helps people perceive architectural spaces and forms. Thus, it is important for architects to handle the light well in their design phases to make a building that accommodates harmonious spaces to en-

\footnotetext{
${ }^{*}$ Corresponding author.
} 
hance the quality of spatiality.

Alvaro Siza, who had little love for unified and formalized architecture, sought the kind of sensual and experiential architecture which was rooted in the region. Siza said "My architecture is not designed with pre-constructed languages. It would not make a unified language to solve all problems. It is a specific reaction of mine to the changing situation I find myself in.” [1]. To understand his architecture is not limited to a unified, single interpretation. In fact, his works are being analyzed by a variety of different approaches.

Frampton, Kenneth [2], for example, referred to his architecture as a form of critical regionalism while emphasizing the use of structure, material and light that blends into the region. In the meantime, Curtis William J. R. [3] described the architecture of Siza as a sculpture in which the city and the landscape are blended with each other. He evaluated that Siza's works had expressed his sensual, intuitive experiences and their interrelationship with the light. In addition, Lee, W. H. [4] explained Siza's methods and characteristics to realize the spatial experiences and analyzed his architecture in terms of the experiential aspects. Park, J. Y. [5] also analyzed the process of changes in the logics Siza used to create the architectural forms. Kwak, S. [6] analyzed one of the most outstanding works of Alvaro Siza, the Aveiro Library, to deduct fundamental value of the light which creates the architectural spaces and forms.

For the study, we selected three works, i.e. the Museum for Ibere Camargo Foundation, the Aveiro Library and the Mimesis Art Museum of Alvaro Siza, which used the natural light as one of the most important elements in order to design the splendid spaces and forms, and then, reviewed existing literatures to understand how he controlled the light and created the architectural spaces and forms in relation with light. The process of this study is as follows:

Firstly, we identified the interrelation between the light and the architecture, which was theoretically studied through examining architectural expression of the light as well as perceptual concept of the light itself. Secondly, we analyzed the architectural backgrounds of Siza in order to understand the fundamental meanings of his architecture such as the critical regionalism, the refined control of the light, the continuity of space, and the relationship between the void spaces and the ambient spaces. Thirdly, we tried to analyze the three representative works of Siza in order to understand the actual methods by which he controlled the light. Finally, we tried to present the architectural values of the light and his conceptual principles in controlling the light.

\section{Light and Architecture}

\subsection{Perception of the Space through the Light}

There are a number of essential environmental elements that affect lives of people. Of these, the light has a tremendous influence over visual perception of people as well as their mentality, and evokes unique feelings from each perceived object. In addition, the variation and fluidity of the light help them notice and feel the changing time. Since a long time ago, the light has been considered as one of the essential elements for architectural design by many architects, and this contributed to the progress of architectural design strategies. By means of light, we recognize and perceive architectural space, and illuminate the interior of buildings. Also, by adding a sentimental side of architecture, it considerably affects the psychological aspect of viewers. It casts dark and bright shadows of forms inside the building, so as to reveal the variation in the physical form of it which gives clue to the users about the rhythmic changes in space. As such, it adds to the functional movements of people an experiential dimension in a more sentimental manner.

The functional role of the light to illuminate the building interior can be different according to the environmental context of the region that building is located. Such locality of the building in relation to the properties of the light is the key aspect in making design strategies on how to induce the light to the inside of the building, how to maintain the brightness, and how to render the inside area of the building comfortable and cozy. Natural light maximizes the coziness of occupants and makes indoor space more refined to enrich our lives in it (Figure 1).

The function of the light in churches or other spiritual buildings is a little different from what we have described above. The religious architecture needs to be enshrined in holiness. In such a space, the light is used to complete the religious nature of it as a symbolic tool. Such spiritual expressions are merged with the spaces by the existence of light and this creates the mysterious and sanctifying aura of the place (Figure 2) [7].

The light guides the movements of people in a building and enables them to perceive spatial characteristics of the building in a more sentimental manner. The light also sheds a differentiated sensation to the place in the building. The influx of the light to a space catches the attention of people in the building and, at the same time, 


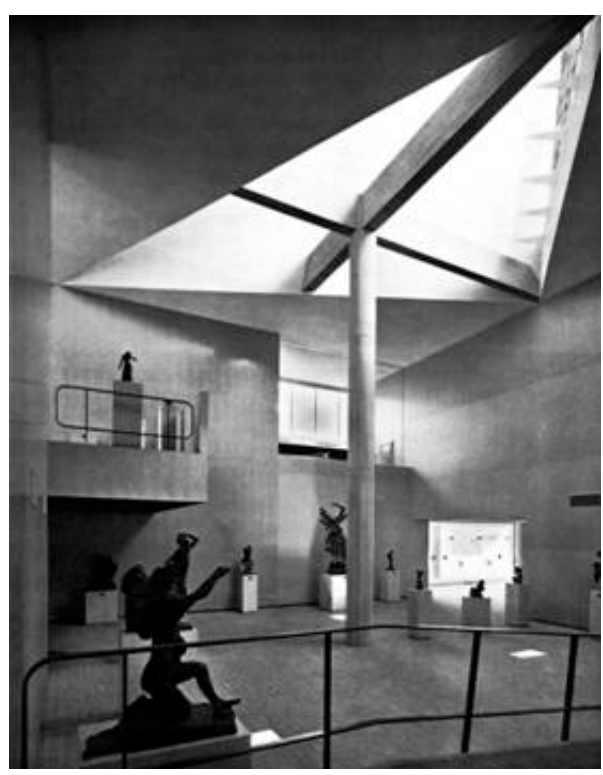

Figure 1. National Museum of Western Art.

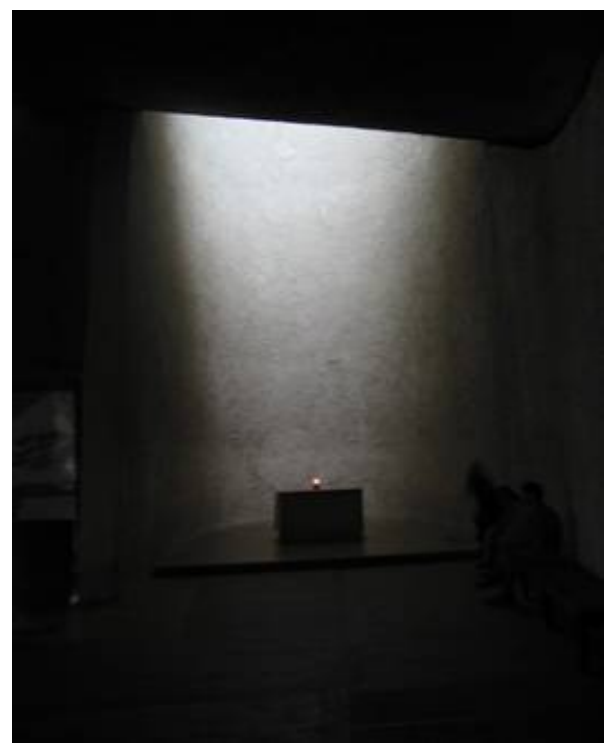

Figure 2. Ronchamp Chapel for Private Oratory.

diverts their attentions, which again facilitates people's circulation in the building. In the building such as museums and churches, the circulation that regulates the sequence of space is a key element. Here, a space makes relations with other spaces, and they are eventually woven one another. While people move around, the light delivers various spatial expressions to them as the influx of the light changes, and it helps them to experience the aesthetic and artistic values of the building. Similarly, by organizing the objects in the space with the shadow, the light helps people experience the building in the sentimental and psychological manners (Figure 3 and Figure 4).

The light changes continuously over time, and it gives changing atmosphere to the space in relation to time. Such fluidity gives life to the space as if it were a living object. Thus, the light gives different feelings to the same physical space as time changes, and such altered feelings affect the sentiment of people. The space itself is in three-dimensional system. However, the light enables people to experience it in four-dimensional system by embracing the dimension of time when it is joined with the light (Figure 5) [8]. 


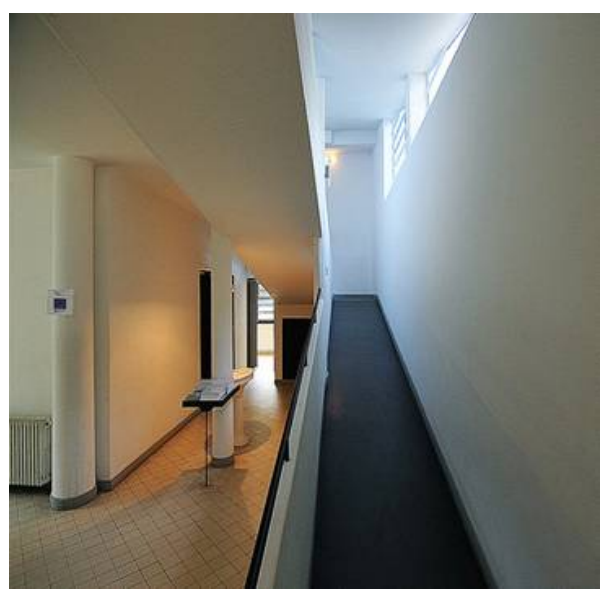

Figure 3. Ramp of Villa Savoy.

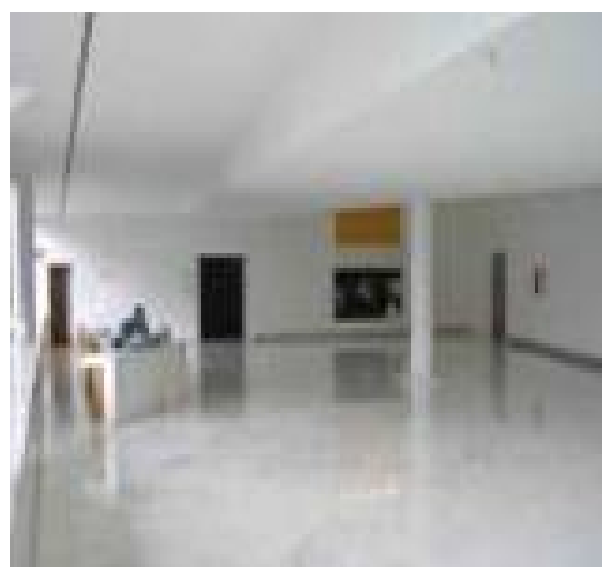

Figure 4. Galician Center for Contemporary Art.
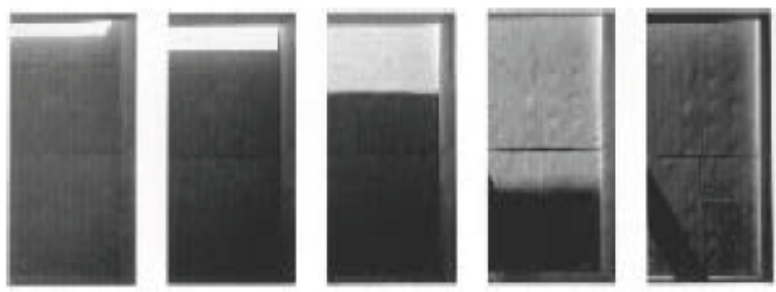

Figure 5. Formation of four-dimensional space by the light according to variation of time.

\subsection{Creation of Architectural Spaces by the Light}

It can be said that architecture is a collection of gathering spaces. It contains daily routines or unpredictable behaviors of people. A Building is consisting of planes, and such planes enclose empty spaces. In order to enhance the qualitative aspect of spaces, it is necessary that a more detailed consideration be given to the expression of the light. There are two spatial techniques to form the architectural spaces by means of light to invoke the actions of people. One is to build cognitive boundaries in space by vertical expansion or contraction of particular spaces. This makes a spatial effect that influences the actions of people by guiding their movements in the buildings. This technique of modulating void spaces is commonly used in art galleries and museums. It can be easily observed in museums designed by Henry Ciriani (Figure 6) and Alvaro Siza (Figure 7).

The other technique which utilizes the height of the space can easily be understood by the spatial diagram by 


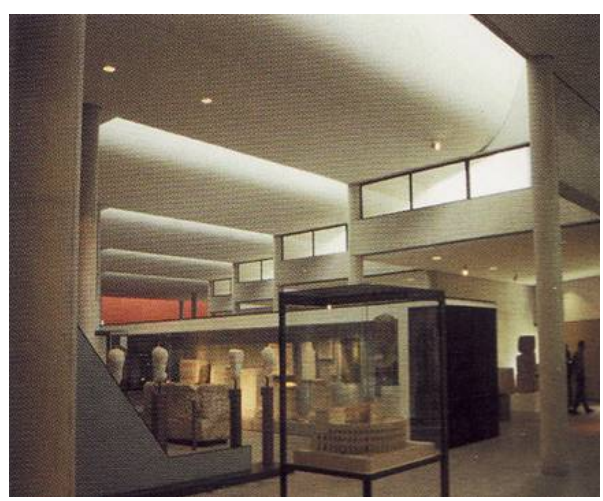

Figure 6. Arles Museum of Archaeology.

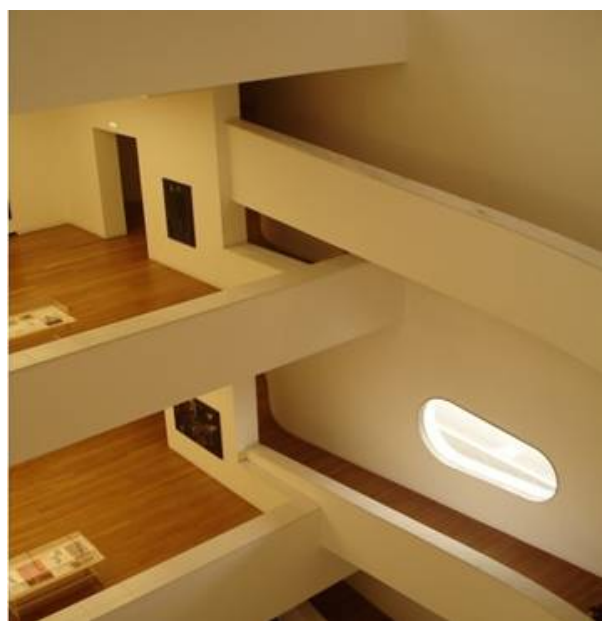

Figure 7. Museum for Ibere Camargo Foundation.

Van Evck (Figure 8). In the diagram, people are sitting in a vessel with their gaze concentrated in a single focal center. Here, the space itself is structured to guide them into looking at the exact point. As such, the vertical height adjustment can guide people into taking a certain action by concentrating and dispersing the line of sight. The sketch of Venice International Convention Center by Louis Kahn can be a good example of spatial arrangement utilizing the vertical height adjustment (Figure 9).

Architectural space has always been containing the lives of inhabitants or users. Such nature of space characterizes architecture, and gives the space its color. However, none of these would become possible without the light. If the light is not manipulated in a proper way, architecture loses its completeness [9]. This, it is not just space or light that gives the meaning of architecture. These two elements should work together in such a way that the space embraces the controlled light inside it (Figure 10).

\section{Characteristics of Alvaro Siza's Architecture}

\subsection{Critical Regionalism with the Strong Regional Tradition and Characteristics}

As Siza said in his interview, "People have very special cultural heritage. However, as they are so preoccupied into the future development, they tend to forget the originality of their traditional culture." [1]. His works establish the concept of regional contexts and unique cultural traditions, in his case from the Portuguese one. His architecture shows the environmental characteristics by means of structuring unique spaces which are created by the indigenous nature of light of the region (Figure 11 and Figure 12) [10].

In his works, the intensity of the natural light has been refined and contained in a space, or within a communal courtyard. Other elements, such as the curvature of the plans completely adapted to the earth and patios that reflect the climate of Portugal, are also in communication with the lives of people and the regional culture. All 


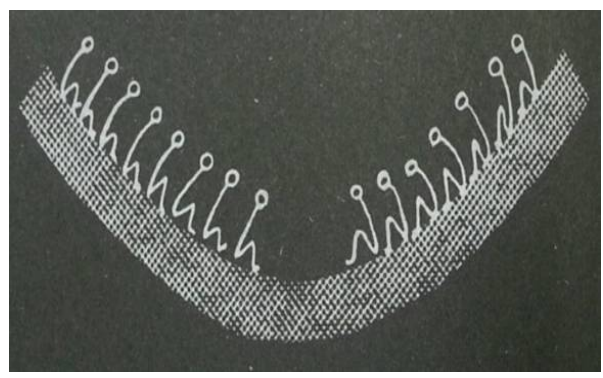

Figure 8. Space Diagram of Jan Van Evck.

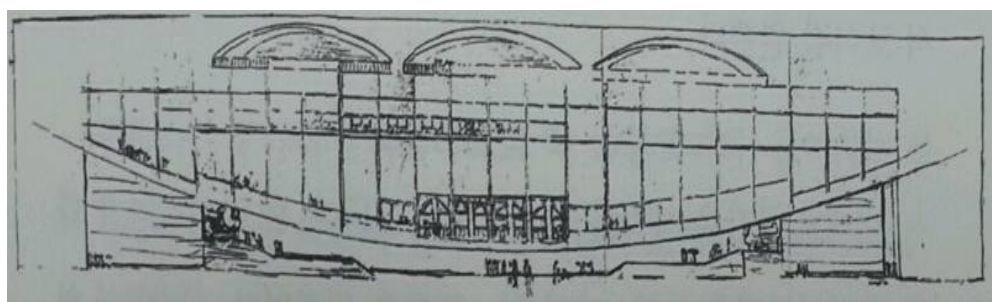

Figure 9. Sketch for Venice International Conference Hall by Louis Kahn.

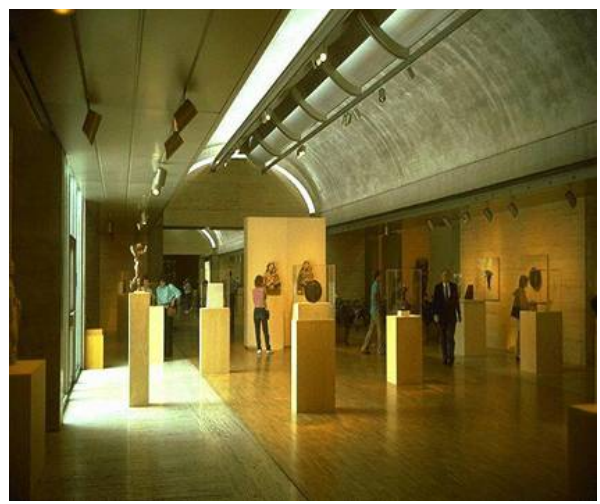

Figure 10. Kimbell Museum.

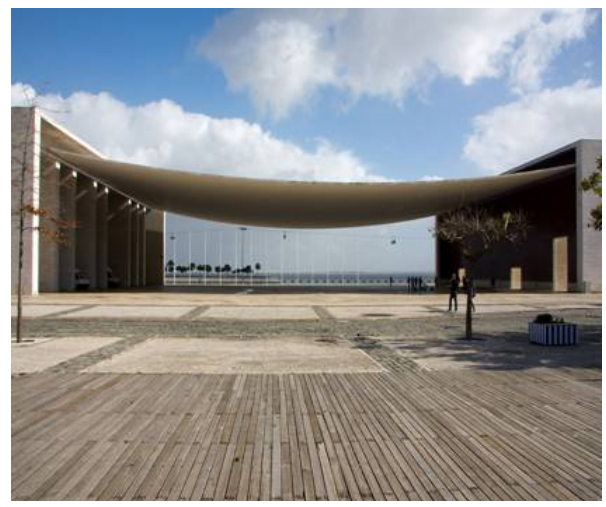

Figure 11. Kimbell Museum.

these contributed to the development of his work. By adapting to the land and using local materials, he created architecture which belongs to the region. He made it a place where the townsfolk gathered and their lives were shared. In a series of process like this, his architecture has been connected to the regional culture and works as a part of urban context (Figure 13 and Figure 14). 


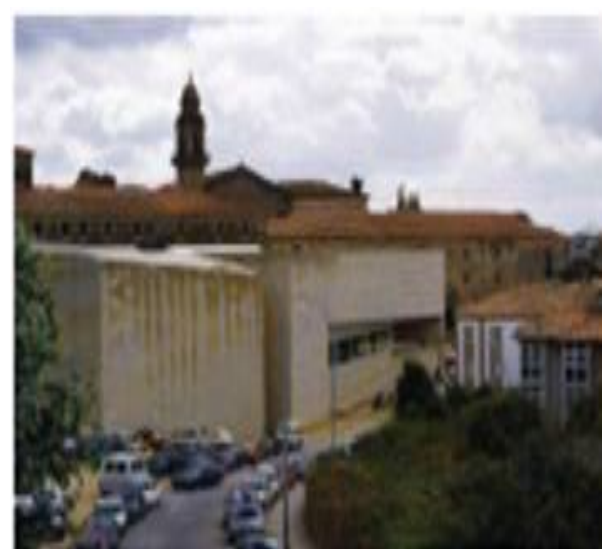

Figure 12. Galician Center for Contemporary Art.

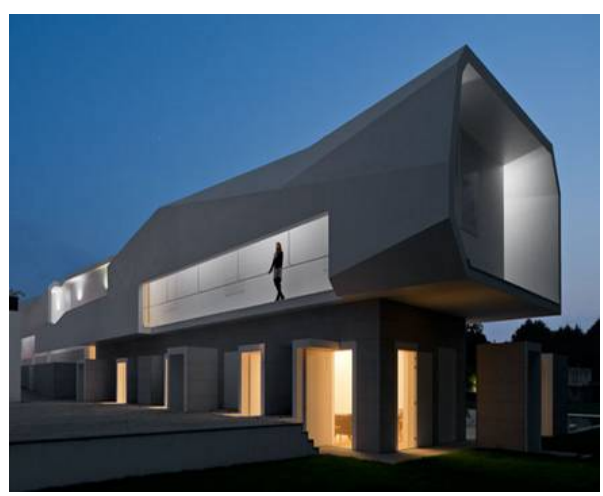

Figure 13. Proto House.

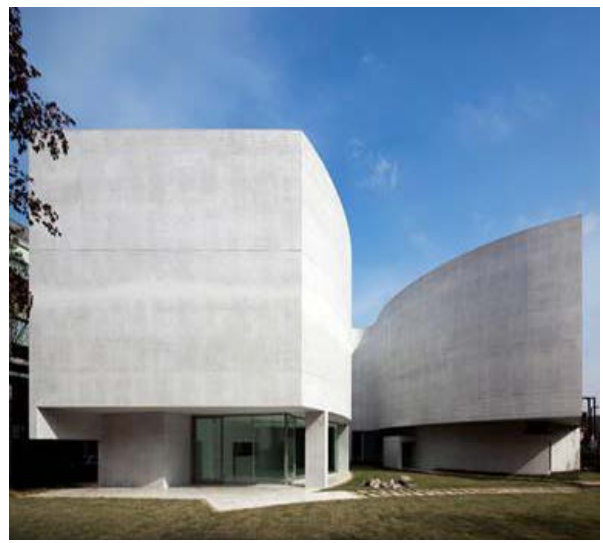

Figure 14. Mimesis Art Museum.

\subsection{Refined Control of the Light and Continuity of the Space}

Curtis, William J. R. once said "The architecture of Siza leaves lasting impressions in the minds of the visitors in many aspects. And, it helps them sensually explore the light, textures, movements, and spaces. The buildings he designed are like vectors that are drawn across the earth. And, they inspire the boost of the experience concerning a place” [3]. Like he said, Alvaro Siza used the light in accordance with climatic characteristics of regions. And, he invited the controlled light into the spaces, making it harmonize with artificial lights laid out inside the building in an appropriate manner in order to create an illuminated space and inspire a refreshing impression (Figure 15 and Figure 16). 


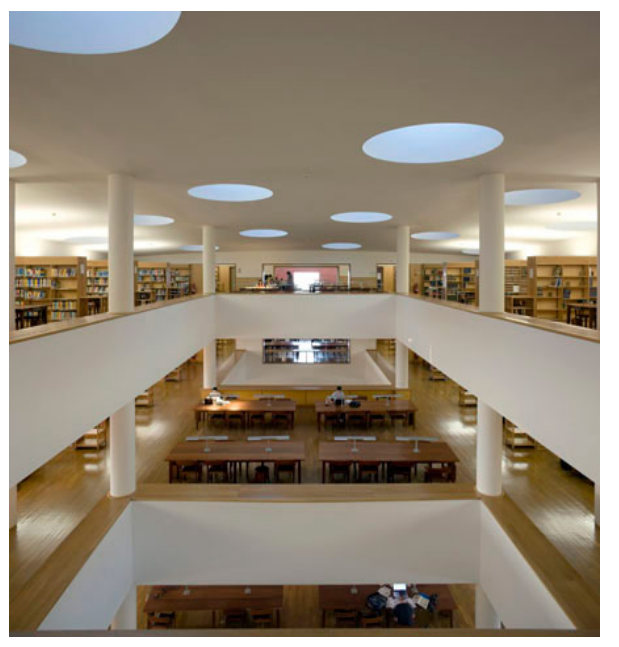

Figure 15. Aveiro Library.

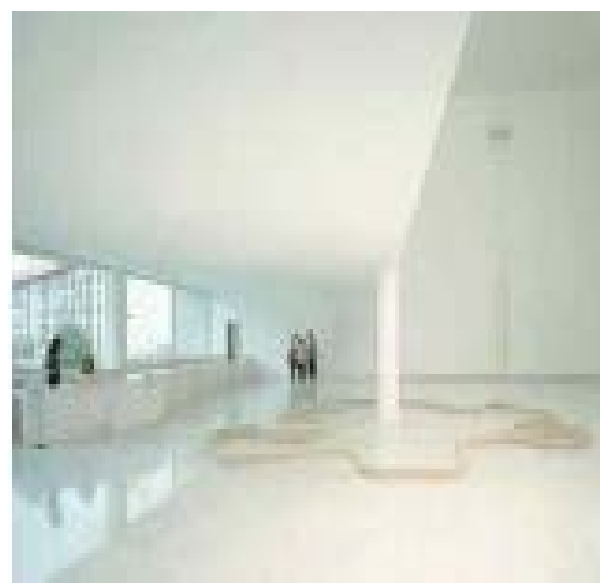

Figure 16. Galician Center for Contemporary Art.

Such spaces created by the influx of the light make people feel a rich sense of space with fluidity by means of the temporal nature of the light. Such continuity of the space can easily be experienced as people explore the inside and outside spaces of building. The shape of the mass observed from outside gives a strong geometric feeling while from the inside it is mingled with light generating a subtle delicacy of geometry. This overturned feelings from the inside and outside spaces provide a unique impression of the spatial continuity to the visitors, and gives psychological stimulation to the visitors to adapt themselves to the spaces [4]. Overall, the changing light in the spaces gives life to the space, which makes the spaces felt more fluid (Figure 17 and Figure 18).

\subsection{Void Spaces and the Relationship with the Surroundings}

One of the characteristics to easily be found in Siza's architectural works is the external courtyards or the internal patios. Such void spaces influence the movements of the visitors in building, as well as the communication between the spaces, and the relationships between land and surrounding areas.

The courtyard of Setúbal University influences the external circulation of the building and the relationship with the surrounding spaces, connecting the spaces around the spaces (Figure 19 and Figure 20). As the visitors walk along the geometric elevations and plans of the building, they come across with an entrance of the building. At this point, the courtyard plays an important role for the movements of the visitors. In addition, it works as the intermediate space to connect the building and the surroundings. A void space alleviates the sense of pressure from the building structure and provides the visitors with a buffer zone between spaces. At the same time, it is where the light is captured to make the inside of the building better-illuminated and felt cozy. 


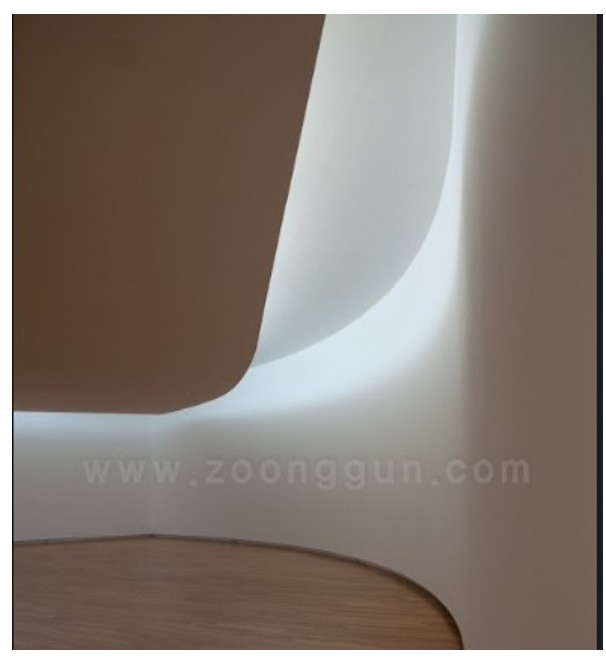

Figure 17. Mimesis Museum.

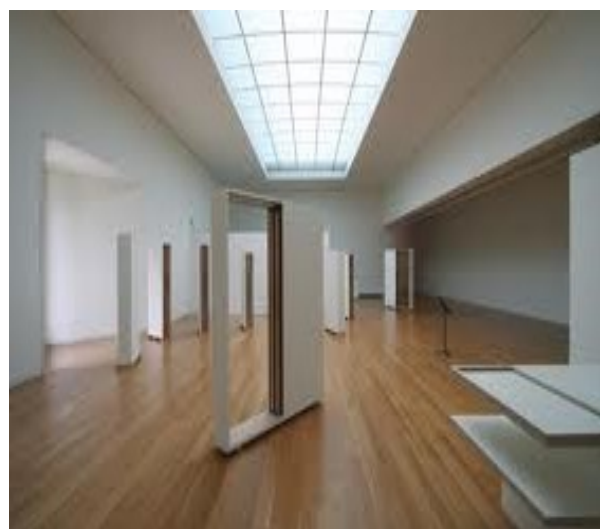

Figure 18. Museum for Ibere Camargo Foundation.

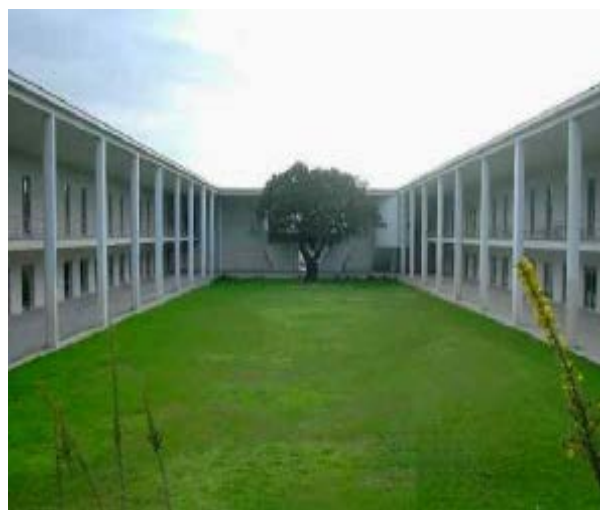

Figure 19. Court in Setúbal Teacher’s College.

By establishing layouts of the building which embraces the land and surrounding areas, the building is equipped with free geometric appearance. With its courtyard, the building establishes an order of the movements of the visitors, and, at the same time, creates a social communication space. Here, the lives of the visitors are accumulated and the space becomes a place to help the visitors experience the architecture in a more dynamic way. In this process, the refined light adds psychological impressions to the minds of the visitors while the building maintains the tradition and conforms to the urban context (Figure 21 and Figure 22). 


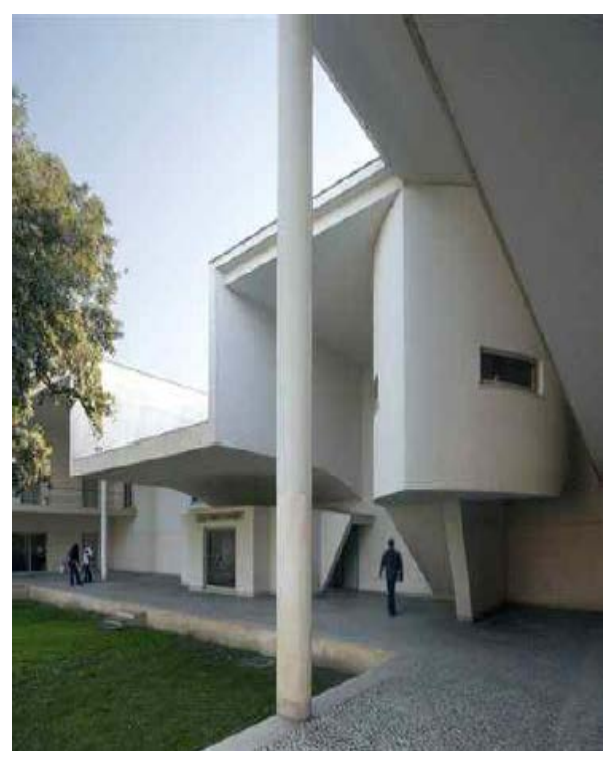

Figure 20. Pilotis of Setúbal College.



Figure 21. Serralves Museum.

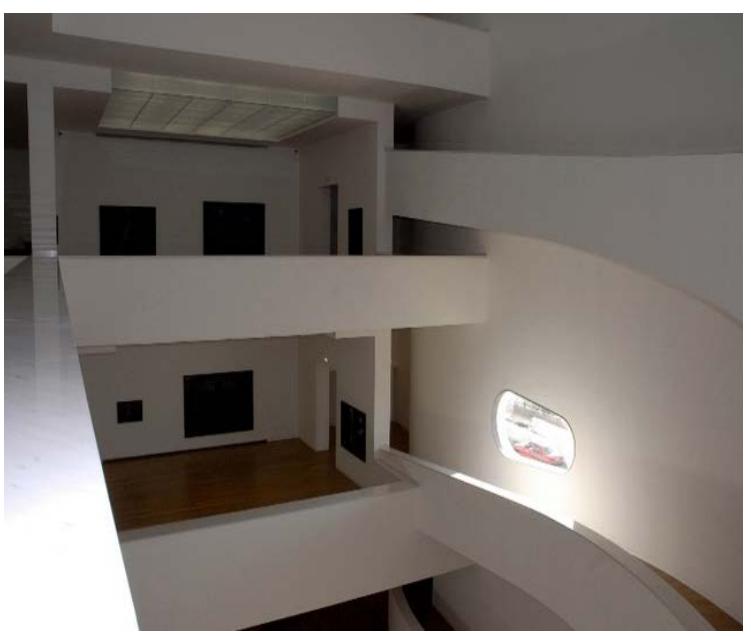

Figure 22. Museum for Ibere Camargo Foundation. 


\section{Case Studies of Alvaro Siza's Works to Show the Relationship between the Light and the Architecture}

\subsection{Museum for Ibere Camargo Foundation}

The Museum for Ibere Camargo Foundation in Porto Alegre in Brazil is one of the new generations of his works that began to appear from 2000. Siza actively adopted void spaces in his design phases, while he created the free, poetic architecture, and kept a strict sense of tradition at the bottom line. The void spaces used in this museum contains the ramps that run across the space, creating a daring and free form of plans that climbs along the void spaces. These ramps come out from the inside of the building, moving to the outside, and then come back to the inside repeatedly while emphasizing the contrast between curves and straight lines. The ramps, once outside, creates another void space, a courtyard, there. This external courtyard becomes the center of the visitors' circulation within the building [11]. At the same time, it provides them with a rich impression of roominess by harmonizing with the light (Figure 23).

Alvaro Siza used side windows to bring the light to the inside of the museum. The light coming in through these side windows blends with the artificial lighting, giving life to the space that is flowing through the flow of walls and ramps. In addition, the windows which are carefully positioned enable visitors to view the nature and invite the spontaneous communications and connections with the surrounding environment. These features make the building as a social place of the region (Figure 24).

\subsection{Aveiro Library}

The Aveiro Library is located in the small city of Aveiro in Portugal. In this building of which the design began in 1987, Alvaro Siza schemed void spaces and unique ceilings to create a dynamic indoor space. The void space located at the heart of the library penetrates the second, third, and fourth floors, vertically expanding the space all the way up to the ceiling. In addition, this void space illuminates the inside of the library by means of the natural light pouring down from the ceiling, while it provides extension of sight for users (Figure 25).

Siza tried to manipulate the light through the careful design of the inclined skylights, curved ceilings and the side windows. The skylight has a conical shape, which is swayed to the North-West. There are 24 skylights aligned diagonally and by interacting with the curved ceiling, they diffuse the natural light throughout the building towards various directions (Figure 26).

The side windows installed in Aveiro Library provide supplementary illumination to the lower stories (Figure 27). The exterior walls in the West let in the indirect light to the space. Such opening designs make the natural light as the primary source of illumination. With this, the Aveiro Library is endowed with the variance of light which changes over time. Joined by the sense of roominess provided by the void space, it makes the sense of rich spatiality.

\subsection{Mimesis Art Museum}

The Mimesis Art Museum, which is located in Paju, South Korea, was designed in a free-flowing geometric shape. When Alvaro Siza was designing this museum, he drew pictures of a cat curled up on the land. He applied these pictures to the building design. The museum in its form looks heavy as a solid mass. However, the pilotis on the first floor supplement the shortcoming of the mass that might have been looked rather dull. In addition, they lead the visitors' movements to easily get to the entrance while offering sufficient opportunities to experience the exterior of the building. Such architectural traits of Siza make the space look much roomier when the visitors enter into the Mimesis Art Museum. Such a subtraction of solid volume in the inner side of the plot is contrasted with tthe closed elevation that borders the road (Figure 28).

The void spaces in the inside and outside of the building are the distinguishing features in Mimesis Art Museum. The void space outside the building is surrounded by curves, giving an impression of variety and continuity in its form. It also helps bring in the light deeper into the building. The void space inside is located in the lobby on the first floor and on the third floor, which vertically connects the two spaces. In addition to the light which is brought in from the nature, this design method allows the visitors to feel the sense of roominess in multiple directions. The museum uses the skylights as the principle light source for illuminating the inside, and they are supplemented by the side windows and artificial lightings that project lights against the white walls. This multiple illumination methods enhance the lighting atmosphere of the building much brighter and cozier (Figure 29). 

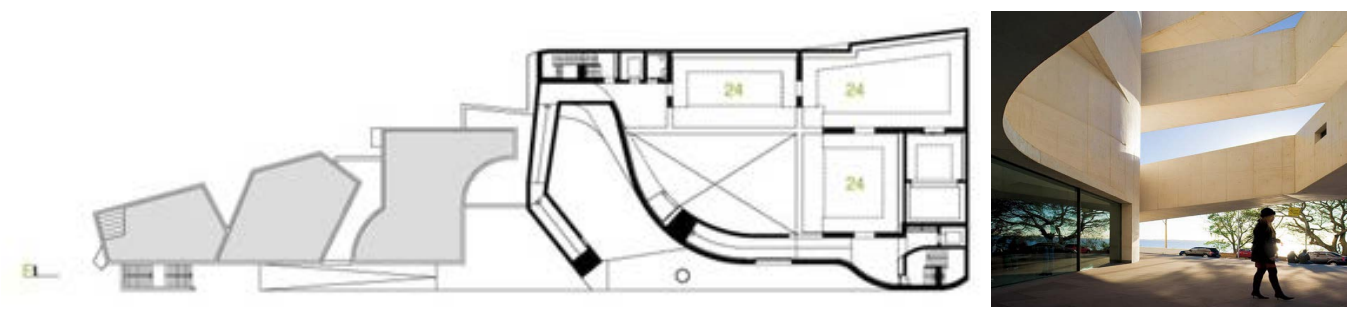

Figure 23. Second floor plan and exterior court.
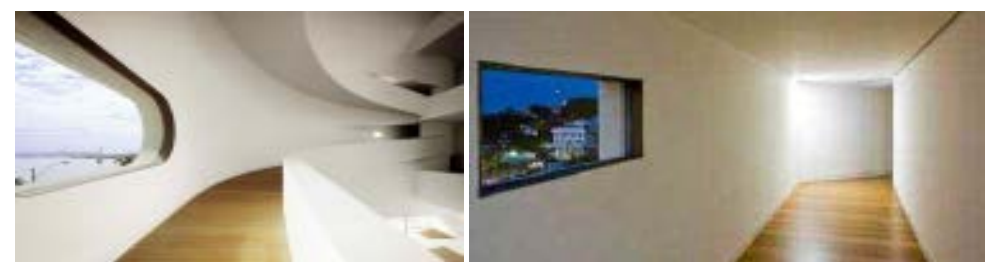

Figure 24. Window pictures.
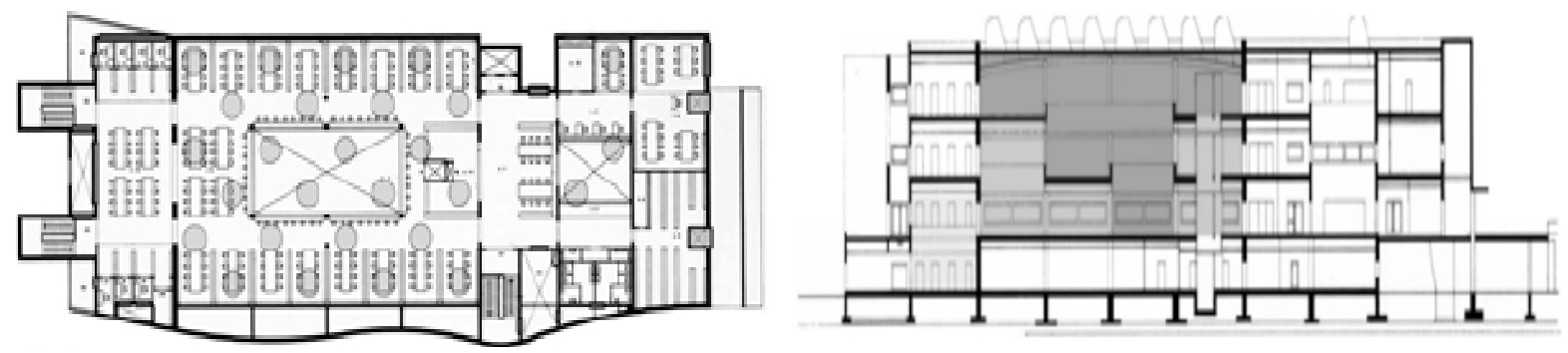

Figure 25. Floor plan and cross section.
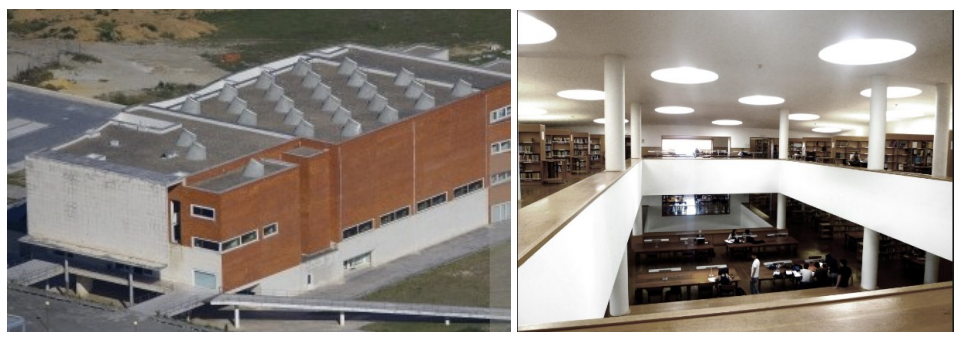

Figure 26. Cone-shaped skylight.
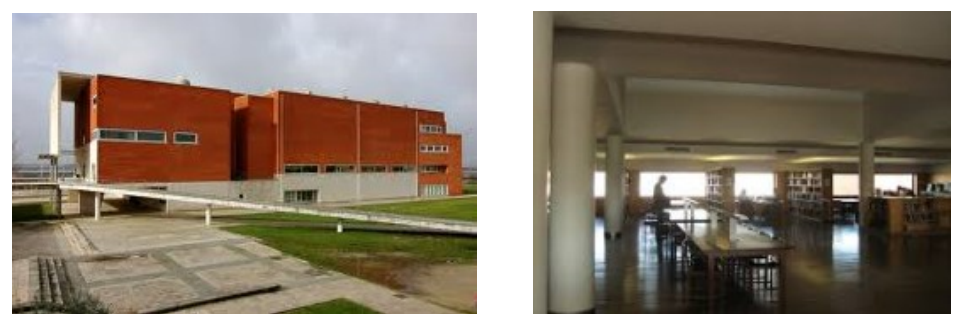

Figure 27. Pictures for Side Windows.

\section{Discussions and Conclusions}

The architecture of Alvaro Siza is not the kind of theoretical architecture trapped inside the formality, but is the sensual and experiential architecture based on the locality. Regarding this, Siza mentioned that his architecture would neither be formed by pre-constructed languages, nor it would make a unified language to solve all prob- 


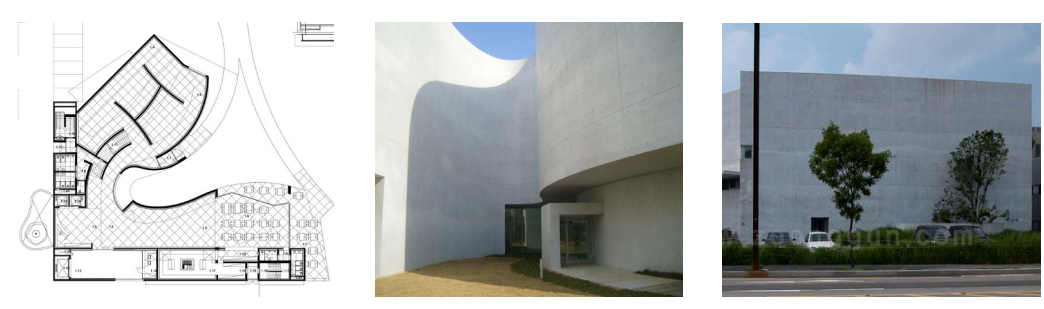

Figure 28. Pictures of the first floor plan, pilotis and building view from highway.

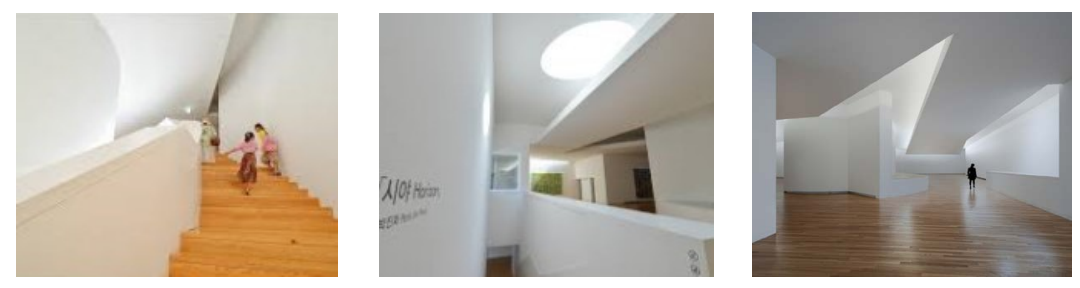

Figure 29. Pictures of grand stair, skylight and exhibition area.

lems. The characteristics of Siza's works examined in this paper may be summarized as follows.

The Museum for Ibere Camargo Foundation showed a set of free, daring, and flowing plans using the ramps that run across the void space. This void space became the center of the visitors' circulation within the building, and provided a sense of roominess in harmony with the light.

The Aveiro Library used a void space which was located at the center of the building, penetrating the 2nd, 3rd, and 4th floors to expand the sense of roominess. The light pouring down from the top of the ceiling illuminated the inside of the library and facilitated the extension of the visitors' vision.

The Mimesis Art Museum placed two void spaces on the inside and outside of the building, which formed a sharp contrast with the dull, massive structure. By providing the diversified and continuing flow of shapes, it also successfully invited the light deeper into the building and was endowed with a sense of continuity that helps guid the visitors' movements.

Alvaro Siza was willing to use the void spaces to invite the light into a building. In his free-flowing plans, the space was invigorated visually as well as physically. In addition, the refined and modulated quality of light in his works helped the visitors' experience of the continuous forms and spaces throughout their movements.

\section{References}

[1] Levit, R.A. (1996) Language, Sites and Types: A Consideration of the Work of Alvaro Siza. The Journal of Achitecture, 1. http://dx.doi.org/10.1080/136023696374668

[2] Frampton, K. (1986) Prospects for a Critical Regionalism. Perspecta: The Yale Architectural Journal, 20, 147-162.

[3] Curtis, W.J.R. (1999) Notes on Invention: Alvaro Siza’, Alvaro Siza 1995-1999. El Croquis, Madrid.

[4] Lee, W.H. (2012) A Study on Alvaro Siza’s Strategy of Realizing Architectural Space Inducing Spatial Experiences: Focusing on the Public Buildings Since 1985, Master Thesis, Seoul National University, South Korea.

[5] Park, J.Y., et al. (1999) A Study on the Changing Process of the Spatial Composition in the Architecture of Alvaro Siza. Proceedings of KIA, 19, 421-426.

[6] Kwak, S., et al. (2010) A Study on the Light in Aveiro Libary of Alvaro Siza. Journal of Korea Institute of Architecture, 26, 45-52.

[7] Kim, C.S. (2012) A Study on the Architectural Expression of the Light Appeared in the Works of Le Corbusier. KIEAE Journal, 12, 71-76.

[8] Kim, K.J. (2000) A on the Variation in Meaning of Architectural Light Since Modern Architecture. Journal of Korean Institute of Interior Design, 25, 213-220.

[9] Lee, K.H., et al. (2012) A Study on the Spatial Tones in Contemporary Architecture in Portugal. Journal of Korean Institute of Interior Design, 21, 100-108.

[10] Chung, H.K. (2014) A Study on the Design Concept of Critical Regionalism through the Contemporary Architecture. Journal of Korean Institute of Interior Design, 13, 20-28. 
[11] Kim, Y.J. (2011) A Comparative Study on Typology and Characteristics of Plan Libre Focusing on 4 Architects. Journal of Korea Institute of Architecture, 27, 269-276. 
Scientific Research Publishing (SCIRP) is one of the largest Open Access journal publishers. It is currently publishing more than 200 open access, online, peer-reviewed journals covering a wide range of academic disciplines. SCIRP serves the worldwide academic communities and contributes to the progress and application of science with its publication.

Other selected journals from SCIRP are listed as below. Submit your manuscript to us via either submit@scirp.org or Online Submission Portal.
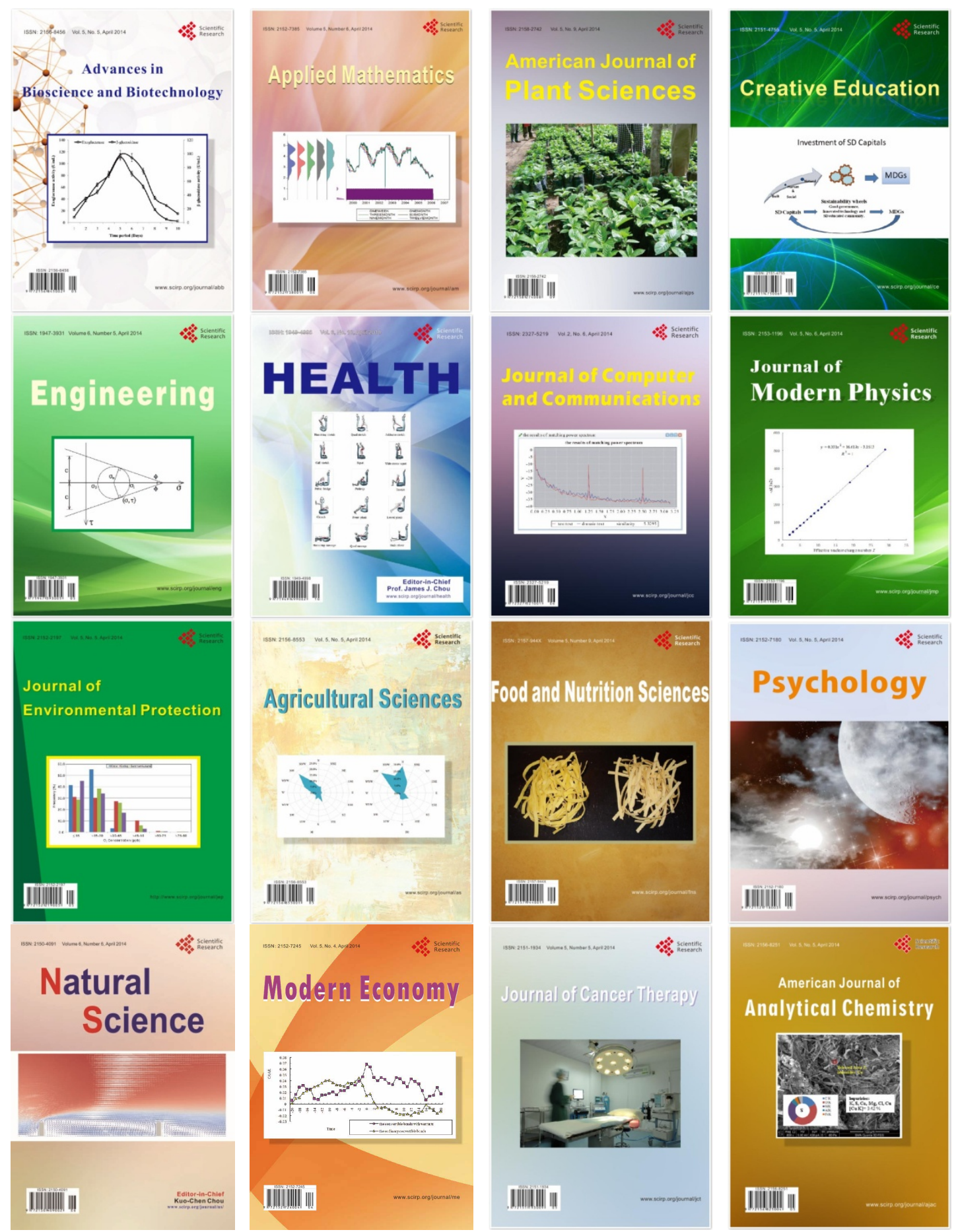